\title{
Multidimensional Poverty and Acute Malnutrition of Children in Households of Mayo-danay Division, Cameroon
}

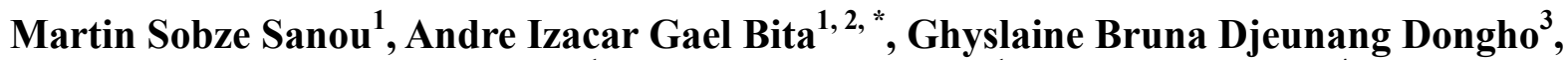 \\ Benjamin Azike Chunkukundun ${ }^{1}$, Armand Tiotsa Tsapi ${ }^{1}$, Isidore Sieleunou ${ }^{4}$, \\ Germaine Sylvie Nkengfack Nembongwe ${ }^{1}$
}

${ }^{1}$ Faculty of Medicine and Pharmaceutical Sciences, University of Dschang, Dschang, Cameroon

${ }^{2}$ Department of Health, Health and Education Action (HEDA), Bengbis, Cameroun

${ }^{3}$ Faculty of Science and Technology, Evangelical University of Cameroon, Mbouo-Bandjoun, Cameroon

${ }^{4}$ Head Office, R4D International, Yaounde, Cameroon

Email address:

bitagael@gmail.com (A. I. G. Bita)

${ }^{*}$ Corresponding author

To cite this article:

Martin Sobze Sanou, Andre Izacar Gael Bita, Ghyslaine Bruna Djeunang Dongho, Benjamin Azike Chunkukundun, Armand Tiotsa Tsapi, Isidore Sieleunou, Germaine Sylvie Nkengfack Nembongwe. Multidimensional Poverty and Acute Malnutrition of Children in Households of Mayo-danay Division, Cameroon. International Journal of Nutrition and Food Sciences. Special Issue: Health and Nutrition: Challenges and Perspectives. Vol. 9, No. 1, 2020, pp. 25-32. doi: 10.11648/j.ijnfs.20200901.15

Received: October 22, 2019; Accepted: December 8, 2019; Published: April 13, 2020

\begin{abstract}
Introduction: The SMART survey (2017) in the Far North region, Cameroon presents high prevalence of malnutrition: $4.5 \%$ of global acute malnutrition (GAM) and 40.9\% of chronic malnutrition (CM). Objectives: To examine the relationship between multidimensional poverty and malnutrition among children under-five in the Mayo-Danay Division. Specifically, assess the nutritional status of children, describe the living conditions of children in households and measure the association between multidimensional poverty and nutritional status of children. Methods: A cross-sectional, descriptive and analytical study was conducted on a cluster sample at two levels. Anthropometric measurements were used to assess the nutritional status of children. The non-monetary, simplified approach, based on the search for deprivation indices of the well-being of children in the household was used. Results: Out of 433 children surveyed, we observed: $4.4 \%$ GAM; $13.9 \%$ of underweight and $23.3 \%$ MC. Out of the $65,82 \%$ poor children, $13,59 \%$ had chronic malnutrition; $2.09 \%$ GAM and $15.00 \%$ underweight. Multidimensional poverty among children was associated with the $\mathrm{CM}(\mathrm{OR}=4,436 ;(\mathrm{CI}=$ 2, $767-7,111)$ and GAM $(\mathrm{OR}=4,194 ;(\mathrm{CI}=1,514-11,416)$. Conclusion: The study highlights the interaction between the living conditions of children in households and the impact on their nutritional status. Multidimensional poverty is associated with malnutrition in children. We recommend to initiate a simulation and comparison study, of poverty reduction scenarios, in the study area.
\end{abstract}

Keywords: Multidimensional Poverty, Malnutrition, Cameroon, Children-under-five, Nutrition

\section{Introduction}

Health is an important indicator of well-being. In particular, the health of children is an indicator of the standard of living of households. Indeed, it is influenced by the environmental, economical, sociocultural and biological characteristics of parents [1]. In Cameroon, Mayo-Danay is the poorest Division in the far North region, with an incidence of poverty of $87.5 \%$ [2]. This Division is often a victim of repeated floods, undermining the stability of its economy. The Division is bordered with Chad on three of its sub-Divisions. It is a cross-border trade area for agricultural products, with the majority of products exported to Chad, and to a lesser extent to Nigeria. Most of the products imported into the region come from Nigeria, among others: yams, wheat flour, potato, sorghum, orange fruit, cowpea, bean, garlic, pasta, soft drink, sugar, peanut seed, goats, rice... [3]. 
Data from the Standardized Monitoring and Assessment of Relief and Transitions (SMART) surveys of 2017 showed a high prevalence of malnutrition in the far North regions, with a prevalence of $4.5 \%$ global acute malnutrition (GAM). Of these, $1.1 \%$ children with severe acute malnutrition (SAM); $40.1 \%$ chronic malnutrition (CM) and $19.2 \%$ underweight [4] Several studies have studied the determinants of malnutrition. According to OSORIO, Ana María et al [5], the context in which the children live affects their health, regardless of the characteristics of the children, their mother, and their household. Communities share physical, social, and economic attributes that may be fundamental to improve the health condition of individuals. The sanitary conditions, education, social networks, and socioeconomic status of communities are factors that are associated with the nutritional status of children. Therefore, the nutritional status of children is associated with the family's standard of living. The demographic and health surveys with multiple indicators of Cameroon (DHS) in 2011 showed that children under the age of five from rural areas are more likely to be victims of malnutrition than those from the urban environment with $40.5 \%$ and $21.9 \%$ respectively for chronic malnutrition, $7.6 \%$ and $3.0 \%$ for acute malnutrition, $20.2 \%$ and $7.2 \%$ for underweight [6].

According to the "summary of humanitarian needs", lack of food, environmental conditions, limited access to health and water, recurrent epidemics (cholera, measles, acute respiratory infection, malaria) associated with low vaccination coverage, and inadequate feeding and hygiene practices are important determinants of malnutrition in the northern part of Cameroon [7]. However, there has been no study on the role of multidimensional poverty on the onset of malnutrition in children under five years of age. The multidimensional poverty index, is a new composite statistical indicator developed in 2010 by a laboratory of the University of Oxford and used by the United Nations Development Program [8]. This index aims to account for the phenomenon of poverty in three of its dimensions: deprivation in education, health and standard of living. This will help to provide scientific evidence of the weight of child poverty in households on malnutrition. The objective of this study was to illustrate the link between multidimensional poverty and malnutrition among children under five in the Division of Mayo Danay. The purpose was specifically to assess the nutritional status of children, describe the living conditions of children in households, and measure the association between multidimensional poverty and the nutritional status of children.

\section{Methods}

We conducted a cross-sectional, descriptive and analytical study of a sample of children, irrespective of gender, from randomly drawn households in the Division of Mayo-Danay. Data were collected during the post-harvest period, in the dry season, from February 26, 2015 to March 8, 2015.

\subsection{Study Population}

The Division of Mayo-Danay grouped in 2014, five health districts including, Maga, Velé, Kar-Hay, Yagoua and Gueré, and 41 health areas and 714 villages/neighbourhoods. The population of this Division was 739268 inhabitants in 2014, of which 124936 children from 0 to 59 months or $16.9 \%$ of the general population of the Division [9]. Several ethnicities lived and shared the Department, among others, the Massas, the Toupouris, the Musgums, the Mousey, the Peuls, the Kanuris, the Kéras etc. The study population consisted of children under the age of five from households in the Department of Mayo-Danay. Only children between 6 and 59 months of age whose parents or care takers of children who have stayed in the study area for at least one month and who have freely consented were included in the study. Children not belonging to the selected households were excluded from the study.

\subsection{Sampling}

This was a two-degree cluster survey. The cluster (village/neighborhood) was the first level of sampling and the household was the second level or unit of investigation. In a household, all target children meeting the inclusion criteria were included in the sample for the measurement of anthropometric parameters. Only one parent or caretaker was interviewed in the household. This procedure was done randomly, from the selection of clusters to the households to be investigated, optimizing representability and limiting selection bias.

The sample size (n) was calculated from the ENA software version 2012, used in SMART nutritional surveys. For an estimated prevalence of $12 \%$, which corresponded to the prevalence of global acute malnutrition among under-5 in the far North region [6], a desired precision of 5\% and a cluster effect of 1.5 , the minimum sample size was 265 Children. Considering an average household size (in the far North) of 5.7 persons [10], 5\% of possible refusal (and absence) of participation and a proportion of $19.6 \%$ of children under 5 years of age in 2015 [10], the ENA software calculated a minimum size $\mathrm{m}=277$ households at investigate in the Division of Mayo Danay. The number of households per village $(\mathrm{u})$ was the number of households to be investigated in total on the number of clusters $(u=m / 30)$, or 9.23 households (10 households were surveyed per cluster). The eleven districts of the Department constituted a single stratum and each village/district constituted a cluster. An exhaustive list of 714 villages/quarters (clusters) of the Division had been introduced into the ENA software entry mask allowing a random draw of thirty clusters. The households were randomly drawn by systematic random sampling by applying a survey step calculated by the teams of trained investigators and according to the pre-established applied procedures.

\subsection{Data Collect Process}

The interview of the participants took place during the day 
or in the evening according to the availability of the households. After obtaining the consent of the head of the family or his legal representative, a questionnaire was administered in a face-to-face interview with the child's mother or caretaker.

Anthropometric Measurements

The calmest children (usually the eldest) were first measured, in chronological order:

(i). Age

Age: it was collected through an official document containing the date of birth of the child or estimated using the local calendar of events or compared to a child whose age or date of birth was known.

(ii). Weight

Weight: the weighing was done using the electronic scale SECA 415 , France, with a maximum capacity of $150 \mathrm{~kg}$. The children were weighed naked, either by direct weighing for the children (13-59 months), or by double weighing for the small children (6 - 12 months) or not being able to stand on the scale. The weight was read and carried in kilograms with a precision of $0,1 \mathrm{~kg}$.

(iii). Brachial Perimeter

Brachial perimeter (BP): the BP measurement was performed in all children on the left arm using a special Ribbon called Shakir band, halfway between the shoulder and the elbow. The arm should hang, be relaxed and loose along the body at the time of reading. The PB measurement was read and recorded to the nearest $\mathrm{cm}$ and millimeter.

(iv). Bilateral Edema

Bilateral edema: the presence of edema was evaluated by a two-inch pressure exerted simultaneously on the back of the child's two feet for 3 seconds. When the thumbprint remained marked on the back of both feet (bucket sign), there was a presence of bilateral edema in the child.

(v). Height/Length

Height/length: it was measured using a Shor measuring tape graduated in $\mathrm{cm}$ and the measure read and recorded in $\mathrm{cm}$ with a precision of $0,1 \mathrm{~cm}$. Children under 2 years of age were measured in the reclining position (length), and those aged 2 years and older in standing position (height).

The thresholds used for classifying children according to their nutritional status from anthropometric indices were classified into three main classes and two subclasses (moderate and severe) per class defined in the following manner:

\subsection{Class One. Acute Malnutrition}

a) Severe acute malnourished (SAM): weight-for-size index less than-3 Z-scores, and/or presence of bilateral edema or brachial perimeter $<115 \mathrm{~mm}$.

b) Moderate acute malnourished: weight-for-size index between- 2 and-3 Z-scores or brachial perimeter $\geq 115$ $\mathrm{mm}$ and $<125 \mathrm{~mm}$.

\subsubsection{Class Two. Stunting}

a) Severe growth retardation: size-for-age index less than3 Z-scores. b) Moderate growth retardation: size-for-age index between-2 and-3 Z-scores.

\subsubsection{Class Three. Underweight}

a) Severe underweight: weights-for-age index less than-3 Z-scores.

b) Moderate underweight: weights-for-age index between2 and-3 Z-.

\subsection{Measuring Child Poverty in Households}

The deprivation approach (non-monetary approach) used in our study to measure poverty [8] is an approach in which poverty is defined as the lack or mismatch in food fields, equipment, standards and common or customary services or activities in a company. We looked for a set of variables to collect in order to identify the deprivations of children in households and build a poverty score. The search for deprivations covered four dimensions. The poverty level of the children here was expressed as a percentage of the deprivations that children faced in the household. For each dimension of well-being, an indicator of poverty reflecting the critical level below which a child (as a person) was considered deprived or poor was defined. In a first step, it was defined for each dimension as a relevant deprivation indicator and a critical level (absolute or relative) considered as a poverty line. We used five dimensions of Matchinidé et al.., [11]. These dimensions were measured with indicators made dichotomic for multidimensional poverty and the calculation of poverty index among children under 5 years of age.

Nutritional dimension: searches for deprivation of the babies from exclusive breast feeding at least six months after birth.

Drinking water dimension: search for deprivations on access to an improved water source according to the classification of the World Health Organization [12]. It was a water under pipeline supplying the home; public fountain/fountain Terminal; tubed well /drilled well; dug wells protected; protected source; drilling. The time spent by someone in the household walking to access an improved or non-improved water source.

Sanitary dimension: research of deprivation on improved toilets, it consisted of flush toilets (towards a sewer system with drains or a septic tank, or a pit latrine); improved ventilated pit latrine (VIP); slab-covered pit latrine; composting latrine [13].

Health dimension: research of deprivations on childcare through the vaccination of children according to their age on the one hand and on the other hand by vitamin $\mathrm{A}$ supplementation (100IU), at least six months after birth.

Living environment dimension: search for deprivations on the normal population index (INSEE standards), either less than or equal to two children per room (dormitory). The nature of the walls, normal or standard wall, hard walls or mud brick walls. The nature of the soil was improved if its material was made of cement/mud brick, tiled/marble. The nature of the roof was said to be improved when the material 
was plate, cement, mud brick.

A second step was to calculate the incidence of poverty of each child, i.e. the number of deprivations in each area of which the child was a victim and to calculate the number of children who had multiple deprivations for the entire possible combinations. Children in the same household could have the same deprivations, in which case information on deprivation was generalized among all children in the household.

To aggregate these dichotomous indicators into a simple composite indicator that has the property to be a good summary of the information provided by the initial indicators, we used the factorial method (multiple correspondence analysis or MCA) used by Asselin [14]. All the indicators used had the same weight. The analytical expression of the composite indicator for a child (I) is written:

$$
C_{i}=\frac{1}{K} \sum_{\boldsymbol{d}_{k=1}} \sum_{J_{K}=1}^{J} W_{J_{K}}^{K} I_{i . j_{k}}^{K}
$$

Where $W_{j_{i}}^{k}$ denotes the normalized score of the category $\mathrm{J}_{\mathrm{k}}$ of the variable $\mathrm{K}$ on the first axis of the MCA of X and $J_{I . J_{i}}^{k}$ a binary variable $0 / 1$ equal to 1 if (i) to category $J_{k}$ and 0 if no. $\mathrm{K}$ is the number of primary variable retained. The $\mathrm{Ci}$ index of an individual (child) was simply the average of the weights of the binary variables Iki, $\mathrm{jk}$.

The child poverty index (\%) was equal to 100 - CI x 100 . The poverty index here thus expressed the percentage of deprivation that the child faced in the household. A child was then considered to be poor multidimensional when deprived in at least 3 of the $10(30 \%)$ areas covered by the indicators. The weight of all scores being "1", so "poor multi dimensionally" had a maximum score of $\leq 30 \%$ and children with a score $\geq 40 \%$ were considered "non-poor multi dimensionally" [8].

\subsection{Ethical Standards Disclosure}

Our study targeted particularly children aged 6-59 months, vulnerable to malnutrition. The selection of the participants for the study was made without distinction of gender, race or ethnicity. The adults selected to answer the questionnaires had given their free verbal consent and the children whose parameters were measured were those whose parent or legal guardian had given verbal consent. Children screened with severe acute malnutrition were referred to the nearest acute malnourished ambulatory nutritional center. In order to ensure confidentiality and secure the information collected during the investigation, the questionnaires were anonymous, the raw data were only accessible to some people and the digital databases were coded. The protection of the participants in our study was based on international regulatory texts such as the Helsinki Declaration, the Nuremberg Code, the Belmont report, the international ethical guide for epidemiological studies developed by CIOMS (Council for international organizations of medical sciences).

\subsection{Statistical Analysis}

The data collected was analyzed by the ENA software version 2012 to classify children according to their nutritional status and to assess the severity of malnutrition. Epi-Info 7 allowed us to perform the various statistical tests at a confidence interval of $95 \%$ and a random error of $5 \%$. The graphs and tables were designed from Excel 2010. It is assumed that the normal range of growth is between -2 and +2 standard deviations, which includes $95 \%$ of the reference population. Z-scores were expressed in standard deviation multiples (ET): A Z-score of 0 was equivalent to the median while it was a Z-score of -2 occurring below the median. Prevalence of malnutrition in under-five children was measured separately for wasting, stunting and underweight. Influence of various socio-economies factors on undernutrition was measured using bivariate analysis. The association between the nutrition status and the standard of living was measured by the Chi 2 test according to whether the value of Odd ration was significant or name, calculated from the software Epi Infos 7.1.40 version.

\section{Results}

\subsection{Socio-demographic Data}

The study was conducted with 433 children, including 220 females $(50.8 \%)$ and 213 male males $(49.2 \%)$. The average age of the children was 30 months, the standard age difference between the children in the sample was 14.70 months. With $27.0 \%$, children aged 6-17 months were the most represented in the sample and 54-59 months at least (4.8\%). Male sex was more represented by the 18-29-month age bracket $(58.0 \%)$ and females by the $30-41-$ month age group $(53.3 \%)$. The age of mothers or children in the household (294 women) ranged from 15 to 87 years, with an average age of 30 years. Among heads of households (278), age ranged from 18 to 85 years, the average age of heads of households was 40 years. The most recurrent age in both types of parents was 30 years. The majority of children's households $(92.59 \%)$ were in united homes (marriage, concubine), $5.05 \%$ were widowers/widows, others separated $(1.35 \%)$ or singles $(1.01 \%)$.

\subsection{Nutritional Status of Children}

Overall acute malnutrition (GAM) in children was 4.4\% (\% $\mathrm{CI}=2.7 ; 7.1)$, underweight at $13.9 \%(\% \mathrm{CI}=10.0 ; 19.0)$ and chronic malnutrition at $23.3 \%(\% \mathrm{CI}=19.0 ; 28.3)$. There was no significant difference in gender for the different forms of malnutrition.

\subsection{Living Conditions of Children in Households}

Only $29.67 \%$ of children were exclusively breastfed for the first six months of life. However, $82.64 \%$ of children had received vitamin A supplementation after their first six months of life (Table 1). More than $67.3 \%$ of children under the age of five lived in households with an improved water 
source. Regarding the distance between households and the water point, $89.12 \%$ of children were from households whose water source (improved and/or not improved) was less than
15 minutes' walk. Finally, children from households with no access to improved sanitation were $87.44 \%$.

Table 1. Distribution of child welfare indices.

\begin{tabular}{|c|c|c|c|}
\hline Well-being indices & Number & $\%$ & CI $(95 \%)$ \\
\hline \multicolumn{4}{|l|}{ Excluisive breastfeeding } \\
\hline yes & 127 & 29,67 & 25,$43 ; 34,29$ \\
\hline no & 301 & 70,33 & 65,$71 ; 74,57$ \\
\hline \multicolumn{4}{|l|}{ Vitamin A } \\
\hline received & 357 & 82,64 & 78,$66 ; 86,02$ \\
\hline Not received & 75 & 17,36 & 13,$98 ; 21,34$ \\
\hline \multicolumn{4}{|l|}{ Water source } \\
\hline Not improved & 139 & 32,63 & 28,$24 ; 37,34$ \\
\hline \multicolumn{4}{|l|}{ Access time to the water source } \\
\hline$\leq 15$ minutes & 385 & 89,12 & 85,$70 ; 91,82$ \\
\hline$>15$ minutes & 47 & 10,88 & 8,$18 ; 14,30$ \\
\hline \multicolumn{4}{|l|}{ Type of toilet } \\
\hline improved & 376 & 12,56 & 83,$85 ; 90,35$ \\
\hline Not improved & 54 & 87,44 & 9,$65 ; 16,15$ \\
\hline Not completed vaccine & 80 & 18,48 & 15,$00 ; 22,53$ \\
\hline \multicolumn{4}{|l|}{ Living environment } \\
\hline Adequate roof & 101 & 23,33 & 19,$48 ; 27,65$ \\
\hline Inadequate roof & 332 & 76,67 & 72,$35 ; 80,58$ \\
\hline Adequate soil & 47 & 10,88 & 8,$18 ; 14,30$ \\
\hline Inadequate soil & 385 & 89,12 & 85,$70 ; 91,82$ \\
\hline Adequate wall & 67 & 15,47 & 12,$27 ; 19,31$ \\
\hline Wall not suitable & 366 & 84,53 & 80,$63 ; 87,73$ \\
\hline Adequate population index & 128 & 29,56 & 25,$35 ; 34,14$ \\
\hline Inadequate population index & 305 & 70,44 & 65,$86 ; 74,65$ \\
\hline \multicolumn{4}{|l|}{ Poverty status } \\
\hline Poor & 285 & 65,82 & 61,$11 ; 70,24$ \\
\hline No poor & 148 & 34,18 & 29,$76 ; 38,89$ \\
\hline
\end{tabular}

Concerning the vaccination status of children, $18.48 \%$ had not received the vaccines recommended for their age (table 1). The distribution of deprivations related to the living environment of children in households is shown in table 1. Of the children, $70.44 \%$ are deprived of an adequate population index ( 1 or 2 children for a household room), $84.53 \%$ are deprived of a household with adequate walls,
$89.12 \%$ are deprived of adequate soil and $76.67 \%$ of a household with an adequate roof for their well-being. The living environment, sanitation and exclusive breastfeeding are the main deprivations that children face in the MayoDanay. The majority of children in households had a score between 3 and 5 (figure 1), with $23.56 \%$ for the score of 3; $24.02 \%$ for the score of 4 and $23.56 \%$ for the score of 5 .

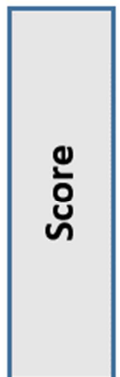

$$
\begin{array}{r}
10 \\
8 \\
6 \\
4 \\
2 \\
0
\end{array}
$$

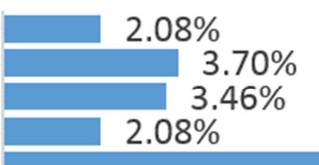

\section{$6.93 \%$}

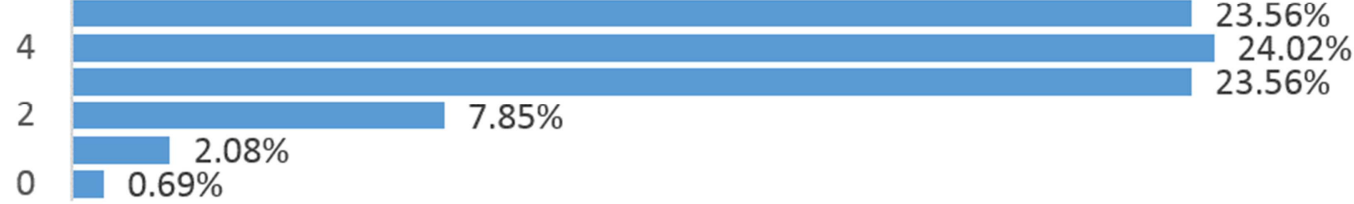

Figure 1. Proportion of children according to deprivation scores (0 to 10).

The proportion of the poorest children with no access to any welfare dimension was $0.69 \%$ and $2.55 \%$ had access to all dimensions. Of the 433 children surveyed, $65.82 \%$ did not have access to more than $30 \%$ (score $\leq 3$ ) of the indicators of well-being in the household.

\subsection{Poverty and Nutritional Status}

The comparison between the nutritional status of children and the status of child poverty (table 2 ) showed that $60,61 \%$ of chronically malnourished children were poor multi- 
dimensionally $(\mathrm{OR}=4,436 ; \mathrm{CI}=2,767 ; 7.111 \mathrm{P}$-value $=$ $0,000)$; and $66.67 \%$ of acute malnourished children were poor multi-dimensionally $(\mathrm{OR}=4,178 ; \mathrm{CI}=1,548 ; 12.298)$; and $70.97 \%$ child with underweight were poor multi- dimensionally $(\mathrm{OR}=0,497 \mathrm{CI}=0,5158 ; 1.7877$; P-value $=$ $0,000)$. The multi-dimensionally poor children are therefore four times more at risk of chronic malnutrition or acute malnutrition than non-poor children.

Table 2. Crossing of nutritional status and child poverty status in households.

\begin{tabular}{lll}
\hline \multirow{2}{*}{ Status poverty } & malnourished & non-malnourished \\
\cline { 2 - 3 } & $\mathbf{N}(\%)$ & $\mathbf{N}(\%)$ \\
\hline Chronic malnutrition & & \\
Poor & $60(60,61)$ & $86(25,75)$ \\
Not poor & $39(39,39)$ & $248(74,25)$ \\
Total & $99(100)$ & $334(100)$ \\
Acute malnutrition & & \\
Poor & $12(66,67)$ & $134(32,29)$ \\
Not poor & $6(33,33)$ & $281(67,71)$ \\
Total & $18(100)$ & $415(100)$ \\
Underweight & & \\
Poor & $44(70,97)$ & $260(72,51)$ \\
Not poor & $18(29,3)$ & $102(27,49)$ \\
Total & $60(100)$ & $371(100)$ \\
\hline
\end{tabular}

\section{Discussion}

The results of our study showed malnutrition prevalence (4.4\%) close to those published by UNICEF in SMART surveys of $2017(4.5 \%)$ in the far North region [4]. This similarity of results confirms the impact of malnutrition in the Far North region and Mayo-Danay division in particular. Exclusive breastfeeding was $29.67 \%$ in the Mayo-Danay Division, this proportion is not very far from that found by DHS of 2011 [6] in Cameroon (20\%), However, the recent surveys show an improvement in the proportion of exclusively breastfed children at national level that is, $40 \%$ according to DHS (2017) [15]. Access to drinking water (improved water source) remains low in the study area, i.e. $67.37 \%$, slightly below the proportion at national level $(71 \%)$ regional level in 2011 according to the DHS (2011). The same source had found a higher proportion (41\%) people with access to improved sanitation against $12.7 \%$ found in our survey. The high proportions of households using inadequate shelters (76.67\% roof; $89.12 \%$ soil; $84.53 \%$ walls and $70.44 \%$ stand index) were predictable because the housing characteristics already reported by the DHS (2011) were nationwide, with $46.3 \%$ of the shelters without electricity; $43.2 \%$ of the shelters with soil or sand covering material, $41.3 \%$ of the shelters, of which more than three people used a sleeping room. These indices of living standards below the national level could be explained by the level of development below other parts of the country and the arid climatic and environmental conditions in the far north zone. These results confirm the classification of the area as one of the poorest divisions of the region, with a poverty index of $71.5 \%$ [2].

The incidence of multidimensional poverty here $(65.82 \%)$ was below that found by Lekeumo [11] with $88.9 \%$. This difference could be explained by the fact that the zone went through a minimum of development between the two periods of study (2007-2015), in addition, several NGOs work in the area to improve access to sanitation, drinking water and infant and young child feeding. On the other hand, the deprivation indices used in our study were adapted to the age group of children under five, whereas those used by Lekeumo [11] assessed multidimensional poverty among children aged 5-17 in the household. The association between the level of poverty and the child's health was already studied by several authors before.

The work of Ahovey and Vodounou [1] in Benin had shown that the standard of living in the household is one of the factors that contribute strongly to reducing the risk for a child to have a stunted growth. According to the authors, an increase of one unit of wealth would reduce the risk of stunting by $0.2 \%$, which is 10 times greater than the effect of the one-year increase in the number of years of study. There is a significant association between "poor multidimensionally" and chronic malnutrition and acute malnutrition. These results confirm those found by Ambapour and Moussana $\mathrm{H}$ [16] according to which the impact of the wealth index is positive and very significant, showing that an increase in household wealth by $10 \%$, would reduce chronic malnutrition $6.3 \%$. According to the same source, the fact that the child belongs to a very poor household exacerbates malnutrition. The work of Ouedraogo (2008) showed specificity in the weight of indices of wealth on chronic malnutrition in children aged five years. In fact, according to the author, wealth improves the health of boys in rural areas. On the other hand, for girls, their nutritional status deteriorates in electrified households and those with a bicycle, and improves with the possession of means of communication (TV, radio) [17]. Mayor et al. (2001), already confirmed the link between the growth retardation and the economic situation in the country. According to the authors, the values are widely dispersed but the prevalence of stunting that spreads between 30 and 50\% for GNP values of $<\$ 300$, drops to $20-30 \%$ for values of $\$ 600-800$. According to the same study, this type of relationship was not observed with the indicator of young children's thinness. This confirms that the indicator of stunting reflects fairly well the overall 
economic status of countries [18]. A more recent study by Khanna et al., (2017) shows an association between all types of malnutrition and socio-economic factors [19].

Our study confirms these results in a more specific way, illustrating the association between poverty and stunting in children under five in households. In the Central African Republic, the probability for a child from a household living in a low-weight lifestyle is $23.2 \%$ higher than that of a child from a household with a high standard of living at the national level. The probability is $63.7 \%$ when the child belongs to a household with a low standard of living, all other things being equal [20]. More recent work by Ossorio et al., (2018), has confirmed the association between standard of living in the household and malnutrition, according to the author, at the level of individuals and households, the probability of malnutrition [5].

In General, nutritional surveys to assess malnutrition in children are conducted during periods of welding. This study was carried out in the post-harvest period, which could lead to a misconception of a decline in the prevalence of child malnutrition in the far North region, compared to the previous years.

\section{Conclusion}

The study showed a high proportion of malnourished children in Mayo-Danay households with $4.4 \%$ of acute malnourished child; underweight: $13.9 \%$ and $23.3 \%$ chronic malnourished. The living conditions of children in households remain precarious, particularly with very limited access to improved sanitation, an inadequate environment and a small proportion of infants who have benefited from exclusive breastfeeding (29.67\%). The study highlighted the interaction between the living conditions of children in households and the impact on their nutritional status of children. In short, children in poor households are more vulnerable to chronic malnutrition and underweight than those with a higher standard of living. The high prevalence of malnutrition in the study area and in the far North region in general requires particular attention both to early diagnosis and to the economy and environment of the household. We recommend conducting a feasibility study for early detection of maternal malnutrition at home (MAMA MUAC). Initiate a simulation and comparison study of poverty reduction scenarios in the study area aimed at improving the living environment of households and promoting care for children to reduce malnutrition-related morbidity among.

\section{Conflicts of Interest}

The authors do not declare any conflict of interest.

\section{Acknowledgements}

We thank the far North regional health delegation for facilitation on the field.

\section{References}

[1] Ahovey EC, Vodounou C. 2003. Multidimensional Poverty and Child Health: Evidence from the 2001 Benin Demographic and Health Survey. Benin; tatistical and Economic Review of INSAE; $\mathrm{p} 42$.

[2] Djoumessi JB, Kom YH. 2013. Measuring and mapping poverty from living conditions. Yaoundé: BUCREP; Vol 2Tome 14, 3e RGPH; 213.

[3] Institut National de Statistique (INS). 2014. Monograph of cross-border exchanges, Cameroon. Yaoundé: INS; p 66.

[4] Nutritional survey and retrospective mortality in women, adolescents and children in cameroon. (East, Adamawa, North and Far north), $2018 . \quad$ available: https://www.humanitarianresponse.info/sites/www.humanitari anresponse.info/files/documents/files/smart_cameroun_2017_ rapport_final.pdf (28/11/2019).

[5] Osorio, Ana María, Romero, Gustavo Alfonso, Bonilla, Harold, \& Aguado, Luis Fernando. (2018). Socioeconomic context of the community and chronic child malnutrition in Colombia. Revista de Saúde Pública, 52, 73. Epub July 26, 2018. 8787.2018052000394 .

[6] Jazet E, Wounang R. 2012. Nutritional status, breastfeeding and feeding practices, Demographic and health surveys and multiple indicators (DHS), 2011. Yaoundé: INS; p 160-180.

[7] Summary of humanitarian needs, Cameroon. 2014. 14p [Retrieved 01/04/2017] Online: https://www.humanitarianresponse.info/system/files/document s/files/HNO_Cameroun_20dec2013.pdf.

[8] Rigaud P, Deubel P, Marsollat P. 2010. The multidimensional poverty index: a new indicator at the service of development policies. Melchior. [Retrieved 01/04/2017] online: http://www.melchior.fr/actualite/lindice-de-pauvretemultidimensionnel-un-nouvel-indicateur-au-service-despolitiques-de.

[9] Nationale Institut of Statistique (INS). 2010. Presentation report of the final results. 3rd General Census of Population and Housing. Yaounde: INS; p 67.

[10] UNICEF. 2013 Nutritional and retrospective mortality survey based on the smart methodology in 4 regions of Cameroon: extreme north, north, Adamawa and east (Cameroonian populations and refugees from the regions of Adamaoua and East). Data collection: July-August 2013. Final Rapport, Cameroon. Yaounde: UNICEF; 51.

[11] Lekeumo SK. 2007. Measurement and analysis of nonmonetary poverty among children: the case of Cameroon. Yaounde: Institut Sous-Régional de Statistique et d'Economie Appliquée (ISSEA); p 62.

[12] OMS. 2004. Quality Directive for drinking water. Geneva, World Organization Health (WHO); 3th ed.; Vol. 1. 110 p. NLM WA 675.

[13] AMCOW. 2008. From: An overview of the situation of drinking water and sanitation in Africa. A regional perspective based on recent data from the Joint Monitoring Program for Water Supply and Sanitation of WHO/UNICEF. Congo: African Minister's Council of Water; $13 \mathrm{p}$. 
[14] Asselin LM. 2002. Multidimensional poverty. Canada: Institute of Mathematics Gauss; $p$ 89-96.

[15] Institut National de la Statistique (INS), et ICF. 2019. Enquête Démographique et de Santé du Cameroun 2018. Indicateurs Clés. Yaoundé, Cameroun, et Rockville, Maryland, USA: INS et ICF.

[16] S Ambapour, Moussana Hylod H. 2008. Poverty and nutritional health of children in Congo. Brazzaville: Office of Application of Statistical and Computer Methods (BAMSI); $p$ 31 .

[17] Ouedraogo S. 2008. Three Essays in Empirical Economics: Education, Health, Gender. Canada: Institute of Applied Economics; HEC; $p 108$.

[18] Maire B, Delpeuch F, Martin-Prével Y, Fouéré T. 2001.
Nutrition and Poverty: A Comparative Review of Anthropometric Surveys in Sub-Saharan Africa in the Last Two Decades. In: WINTER GERARD (COORD.). Inequalities and public policies in Africa: plurality of norms and stakeholder. Paris: Institut de Recherche et Développement (IRD); p 57-71. ISBN 2-84586-141-9.

[19] Khanna P, Kaur R, Singh T, Miller J, Sandhu A. K, Jyoti. Prevalence and Socio Demographic Determinants of Malnutrition in Rural Communities of District Fatehgarh Sahib, Punjab. Curr Res Nutr Food Sci 2017; 5 (3). doi: http://dx.doi.org/10.12944/CRNFSJ.5.3.23.

[20] Matkoss FE. 2003. Household Poverty and Malnutrition of Children Under Five in the Central African Republic. Yaounde: Institute of Training and Demographic Research (IFORD); $\mathrm{p}$ 166. 